\title{
Answer to: Micronutrient Supplementation after Biliopancreatic Diversion with Duodenal Switch in the Long Term: Using Refill Bypass Is the Solution
}

\author{
Philipp C. Nett ${ }^{1,2}$
}

Published online: 26 May 2016

(C) Springer Science+Business Media New York 2016

Vitamin and mineral deficiencies following malabsorptive bariatric surgery such as Roux-en-Y gastric bypass (RYGB) or biliopancreatic diversion with duodenal switch (BPD-DS) are an underestimated problem under general surgeons, especially after longer periods of surgery [1-3]. To avoid these long-term consequences of vitamin and mineral deficiencies, we therefore again emphasise that repeated and life-long monitoring at a specialised bariatric centre is needed to detect and treat deficiencies at every stage after malabsorptive bariatric surgery [3]. We agree that for some macro- and micronutrients (e.g. protein, iron, vitamin $\mathrm{B}_{12}$, and vitamin $\mathrm{D}$ ), malnutrition issues are already reasonably addressed through patient education, routine monitoring, and effective treatment strategies (e.g. oral, sublingual, intramuscular, or intravenous) [4].

Philipp C. Nett

philipp.nett@insel.ch

1 Department of Visceral Surgery and Medicine, Inselspital, University Hospital Bern, University Bern, Bern 3010, Switzerland

2 Leiter universitäres Adipositaszentrum Bern und Leiter bariatrische und metabolische Chirurgie, Universitäre Klinik für viszerale Chirurgie und Medizin Inselspital, Freiburgstrasse, 3010 Bern, Switzerland
However, there is little attention paid to other nutrients (e.g. zinc, copper, and selenium), which if left untreated may have devastating consequences (e.g. weak immunity or defects in neuromuscular function) and which is in general not paid by the health insurances although of supplementation prescription.

\section{Compliance with Ethical Standards}

Conflict of Interest The authors declare that they have no conflict of interest.

\section{References}

1. Bal BS, Finelli FC, Shope TR, et al. Nutritional deficiencies after bariatric surgery. Nat Rev Endocrinol. 2012;8(9):544-56.

2. Topart P, Becouarn G, Salle A, et al. Biliopancreatic diversion requires multiple vitamin and micronutrient adjustments within 2 years of surgery. Surg Obes Relat Dis. 2014;10(5):936-41.

3. Nett PC, Borbély Y, Kröll D. Micronutrient supplementation after biliopancreatic diversion with duodenal switch in the long term. Obes Surg. 2016 Mar 17. [Epub ahead of print]

4. Gletsu-Miller N, Wright BN. Mineral malnutrition following bariatric surgery. Adv Nutr. 2013;4(5):506-17. 